\title{
Article
}

\section{Physical Exercise and the Prosocial Behaviors of Students in China}

\author{
Yi Wan ${ }^{1}$, Lian Lv ${ }^{2}$ and Hong lian Song ${ }^{1, *}$ \\ 1 Department of Physical Education, Nanjing Forestry University, Nanjing 210037, China; wanyi@njfu.edu.cn \\ 2 School of Business and Trade, Nanjing Vocational University of Industry Technology, Nanjing 210023, \\ China; lvl@niit.edu.cn \\ * Correspondence: 11681212@163.com Tel.: +86-25-85427731
}

\begin{abstract}
Based on the 2014-2015 China Education Panel Survey (CEPS) and using the propensity score matching method, we studied the causal relationship between physical exercise and prosocial behavior of junior middle school students in China. Ordinary least squares regression and propensity score matching estimation results showed that participation in physical exercise significantly increases students' prosocial behavior by more than 0.2 standard points. The results of this study were tested and found to be robust.
\end{abstract}

Keywords: sports participation; junior middle school students; prosocial behavior

\section{Introduction}

There is currently a movement in China to strengthen physical exercise programs for primary and secondary school students to enhance their physical fitness. In 2020, the Central Committee of the Communist Party of China (CPC) announced the Opinions on deepening the integration of sports and education to promote the healthy development of youth. In the Opinions, the CPC further emphasized the need to strengthen sports in schools and assist students in enjoying physical exercise, improving their physique, developing their personality, and exercising their will. The central government's emphasis may reflect the current severe lack of physical activity among youth and adolescents.

Current research has shown that physical exercise assists in improving physical fitness and students' mental health [1-3]. However, few studies have considered the effects of physical exercise on people's moral quality or the moral fitness of an entire society. Furthermore, the British Charities Aid Foundation has reported that China has the lowest level of helping behaviors among its citizens. As a result, it is important to study whether physical activity has any significant effects on students' prosocial behavioural tendencies.

Prosocial behavior is an important aspect of an individual's fitness. Research indicates that prosocial behaviors are important in determining adolescents' academic performance, interpersonal relationships, physical and mental health development, and socialization [4-8] also found that a person's prosocial preference significantly improves their labor market performances. As a result, how to improve a person's prosocial tendencies is an important issue.

According to current research, there are numerous avenues by which physical exercise may improve the prosocial behavior of individuals. First, physical exercise can increase individual empathy, promote individual collective participation, and increase trust between people, thereby enhancing individual prosocial behavior [9]. Second, physical exercise improves an individual's mental health so that the individual is in a more optimal emotional state, and it is easier to implement prosocial behaviors. For example, studies find that physical exercise can significantly reduce individual depression and increase happiness [10]. Physical exercise may increase the interaction between people, thereby increasing their prosocial behavior tendency [8]. Therefore, sports should have a positive 
impact on many aspects such as the degree of individual socialization and social adaptability.

\subsection{Prosocial behaviors}

Prosocial behaviors are defined as behaviors that meet social expectations and are beneficial to others, groups, or society [11-12]. This definition includes not only behaviors that benefit the recipient, but also behaviors that promote positive interpersonal relationships between both parties [13]. It also contains individuals' positive behaviors such as friendship, help, and sharing in interpersonal communication [14].

Prosocial behavior is motivated by many factors, including individual factors and environmental factors. The individual level includes four aspects: empathy [15], viewpoint selection [16], emotion [17], and personality [18]. At the level of environmental factors, both family and school have an important influence on prosocial behavior [19], where environmental factors usually include social interactions with family members and other people.

Van Tongeren and Green [20] provide evidence that prosocial behaviors play a crucial role in adolescents' academic performance, interpersonal relationships, physical and mental health, and socialization. Layous et al. [21] demonstrate that a person's prosocial behaviors play important roles in their social adaptation and social harmony.

For the individual, prosocial behavior helps to improve self-esteem[22], bring a sense of meaning [23], cope with negative emotions such as anxiety and loneliness [24], increase individual happiness[25] and life satisfaction[26], and obtain a higher level of mental health.

From a social perspective, prosocial behavior is an important foundation for the construction and maintenance of a harmonious society [27], and it has a positive effect on promoting the progress of social civilization.

\section{2. research on the effects of participation in physical exercise}

Current research on the effects of participation in physical exercise began with the relationship between physical exercise and cognitive performance. A large body of literature has provided evidence that physical activity plays important roles in improving children's cognition and academic achievement[28-30], and even finds that regular participation in physical exercise may have a positive effect on improving adolescents' creativity and shortening reaction time. In the past 10 years, studies have gradually included the investigation of factors such as family economic and cultural background (ESCS), body mass index (BMI), adolescent physical level, and parental participation, and at the same time, increased the focus on cognitive ability [31].

Many studies have also explored the relationship between physical exercise and the mental health of adolescents. Mata eta al. [32] stated that physical exercise can promote the secretion of brain-derived neurotrophic factor (BDNF), which produces positive mental states such as happiness and satisfaction. Goodwin [33] conducted a survey of 8,089 U.S. citizens and found that physical exercise is negatively correlated with psychological symptoms such as anxiety and depression.

A study by Biddle and Asare [34] indicated that physical exercise has obvious effects on alleviating anxiety, depression, and improving mental state. Vocks et al. [35] noted that physical exercise has positive effects on immediate body image and mood. Caldwell et al. [36] showed that long-term participation in sports and mastering sports skills can improve the exercise self-efficacy of sports participants. Ede et al. [37] found that long-term participation in sports can increase athletes' self-confidence and self-esteem. Campbell [38] stated that the enhancement of physical fitness also helps to increase the organism's ability to resist stress and tension and to function normally under stress and tension.

Some research investigated the relationship between physical activity and individuals' prosocial behaviors. However, most studies are only concerned with the effects of 
prosocial preferences on physical activities. For instance, Moore et al. [39] stated that prosocial behavior plays an important role in physical activities.

The major deficiency with the current research is that there are few studies that have examined the effects of physical exercise on prosocial behavior. Specifically, some research has considered the relationship between physical exercise and prosocial behavior, but the causal relationship was not explored.

The purpose of this article is to use the China Education Panel Survey (CEPS) to study the influence of regular participation in physical exercise on students' prosocial behaviors, and to study the use of physical exercise as a means to develop the prosocial behavior of junior high school students. Theoretically, it is proved that physical exercise affects students' behavior and moral quality, so as to provide a reference for related practice. Studying the impact of physical exercise on students' moral qualities will also assist in increasing our understanding of the role of physical exercise in students' lives and increase the relevant literature.

There are two main findings of our study. First, estimates of ordinary least squares (OLS) regression and propensity score matching (PSM) suggest that physical exercise has significant and positive effects on students' prosocial behaviors. Second, females receive greater benefits from physical exercise as compared to males.

\section{Materials and Methods}

\subsection{Data}

The data used in this article originate from the 2014-2015 China Education Panel Survey (CEPS). CEPS is implemented by the China Survey and Data Center of RUC. This is the first continuous and large-scale follow-up survey project for young students starting from the junior high school stage in our country. The survey adopted a probability sampling method proportional to size, whereby 4 schools in 28 counties (districts) were randomly selected according to grade (first grade and third grade of junior high school). The data cover 112 schools, 438 classes, and approximately 20,000 students nationwide. The subjects of the survey include students, parents, teachers, and school leaders. The data are mainly based on students, and various factors such as students' basic individual characteristics, family characteristics, school characteristics, and students' cognitive and noncognitive abilities were investigated.

For this article, the main advantage of CEPS is that it investigates both students' physical exercise behaviors and prosocial behaviors. Regarding their physical exercise behavior, CEPS asked "You usually do physical exercises _ days a week, _ minutes a day". Because 5 days is the upper $75 \%$ cut-off point for the frequency of participating in physical exercise, if a student performs physical exercise for more than 5 days a week, he or she would be considered in the current study to regularly participate in physical exercise.

Regarding prosocial behavior, CEPS asked, "In the past year, did you improve the following points?" "Helping the elderly do things", "Obeying orders, consciously queuing up" and "Being sincere and friendly to others". The answer includes five options, which are "never, occasionally, sometimes, often, and always", relative to assigning 1, 2, 3,4 , and 5 points, respectively. We added the answers to the three questions and obtained the total prosocial behavior score.

Herein, we processed the data as follows. Students whose daily exercise time is in the $99 \%$ quantile were excluded. These students exercise more than 6 hours a day on average, and the longest was even more than 24 hours, which indicates that there may be errors in these data. Then, we distinguished urban household registration samples, rural household registration samples, and residential household registration samples.

It is evident that there are huge differences between urban and rural families in our country. Such family differences may be reflected in the differences in behaviors of students. Our country's household registration system has been loosened in recent years, and some areas have carried out household registration reforms, unifying urban and rural household registrations into residential household registrations. Even so, the difference 
between urban and rural areas remains, and will not disappear in a short time after the unified household registration. Moreover, household registrations are different from rural household registrations and urban household registrations.

The main control variables in this study include the basic demographic characteristics of students, including gender, age, ethnicity, BMI, cognitive ability, number of siblings, father's education, and mother's education. Because the students are all eighth graders, we do not need to control the education stage. The statistical description of the main variables is shown in Table 1.

Table 1. Variable statistical description.

\begin{tabular}{|c|c|c|c|c|}
\hline Variable & $\begin{array}{c}\text { Full } \\
\text { sample }\end{array}$ & $\begin{array}{c}\text { Rural } \\
\text { household }\end{array}$ & $\begin{array}{c}\text { Urban } \\
\text { household }\end{array}$ & $\begin{array}{l}\text { Resident } \\
\text { household }\end{array}$ \\
\hline \multirow{2}{*}{ Prosocial behavior } & 11.4440 & 11.2460 & 11.7941 & 11.4866 \\
\hline & $(2.2396)$ & $(2.2329)$ & $(2.1308)$ & $(2.3407)$ \\
\hline \multirow{2}{*}{ Physical exercise } & 0.3602 & 0.3394 & 0.3689 & 0.4030 \\
\hline & $(0.4801)$ & $(0.4736)$ & $(0.4826)$ & $(0.4907)$ \\
\hline \multirow{2}{*}{ Gender } & 0.4854 & 0.4741 & 0.5300 & 0.4540 \\
\hline & $(0.4998)$ & $(0.4994)$ & $(0.4992)$ & $(0.4980)$ \\
\hline \multirow{2}{*}{ Age } & 11.5219 & 11.6252 & 11.3766 & 11.4487 \\
\hline & $(0.6890)$ & $(0.7565)$ & $(0.5655)$ & $(0.6065)$ \\
\hline \multirow{2}{*}{ Han nationality } & 0.9147 & 0.9064 & 0.9175 & 0.9327 \\
\hline & $(0.2794)$ & $(0.2914)$ & $(0.2751)$ & $(0.2506)$ \\
\hline \multirow{2}{*}{ BMI index } & 19.1913 & 18.9621 & 19.3826 & 19.5333 \\
\hline & $(3.3188)$ & $(3.1892)$ & (3.3992) & $(3.4937)$ \\
\hline \multirow{2}{*}{ Cognitive ability } & 3.1165 & 3.0785 & 3.1865 & 3.1207 \\
\hline & $(0.3129)$ & $(0.3193)$ & $(0.2722)$ & $(0.3307)$ \\
\hline \multirow{2}{*}{ Number of siblings } & 0.7001 & 0.9567 & 0.3608 & 0.4886 \\
\hline & $(0.8190)$ & $(0.8446)$ & $(0.6137)$ & $(0.7655)$ \\
\hline \multirow{2}{*}{ Mother's years of education } & 9.7377 & 8.4300 & 11.4457 & 10.8452 \\
\hline & $(3.3024)$ & $(2.8579)$ & $(2.9738)$ & $(3.3514)$ \\
\hline \multirow{2}{*}{ Father's years of education } & 10.4320 & 9.2378 & 12.0052 & 11.4252 \\
\hline & $(2.8638)$ & $(2.2801)$ & $(2.7058)$ & $(3.0325)$ \\
\hline Observed value & 7666 & 4037 & 2098 & 1531 \\
\hline
\end{tabular}

Note: Standard errors are in parentheses.

The distribution of prosocial behavior scores for whether to regularly participate in physical exercise is shown in Figure 1. It shows that the scores of prosocial behavior for students who regularly participate in physical exercise are obviously more concentrated in the high stage, while those who do not often participate in physical exercise are more concentrated in the low stage. This shows that regular participation in physical exercise can significantly improve students' prosocial behavior. 


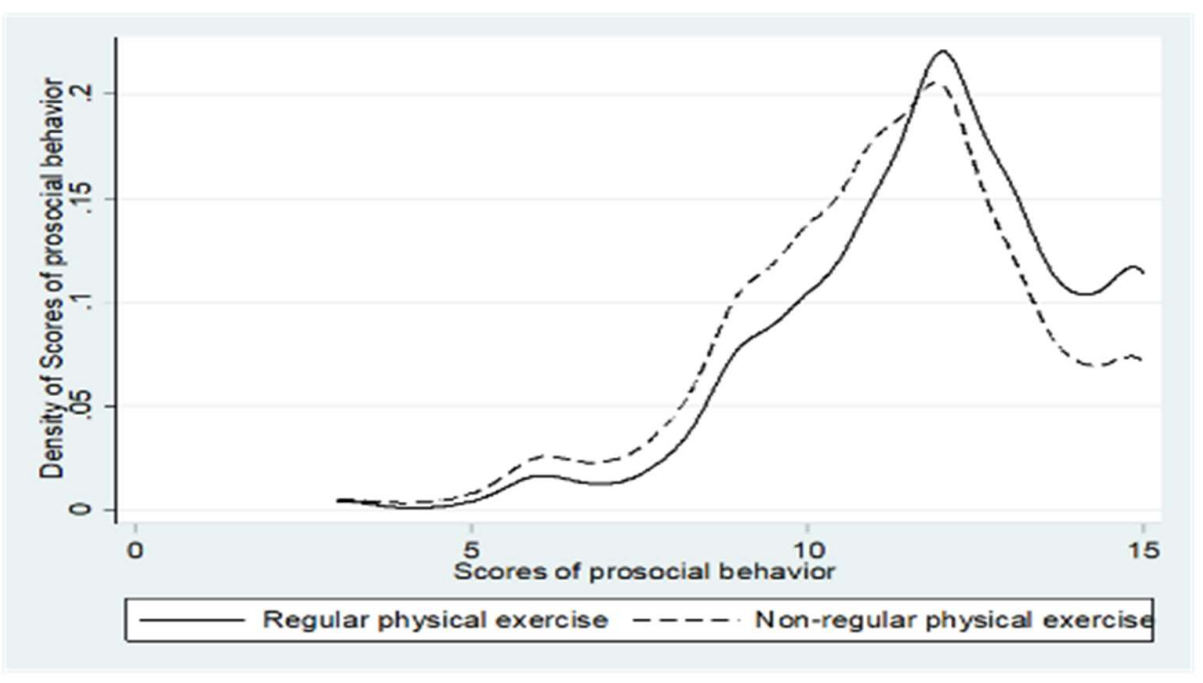

Figure 1. The distribution of prosocial behavior scores for whether to regularly par ticipate in physical exercise.

\subsection{Identification strategy}

Normally, we use a linear model to estimate the impact of physical exercise: prosocpref $=\alpha+\beta$ sport $+\gamma X+\varepsilon$ sport $=I[\pi X+v>0]$

Here, the prosocpref is the score of the student's prosocial behavior, and the sport is whether the student participates in sports. If the student often participates in physical exercise, its value is 1 ; otherwise it is 0 . The $X$ represents other control variables. The $\varepsilon$ and $v$ are the error terms. The $\beta$ is the influence coefficient of the sports we are concerned about. We expect that sports will have a significant positive impact on students' prosocial behavior.

It is worth noting that if the impact of physical exercise is directly estimated, there may be a problem of estimation bias caused by selection bias. It is possible that students who regularly participate in physical exercise are individuals who enjoy social activities, master higher social skills, and have higher prosocial behavior tendencies. Those students who do not or rarely participate in physical exercise are people who do not like social interaction, and therefore have low prosocial tendencies. This indicates that our estimation results are biased. The traditional method to solve this problem is to determine instrumental variables that affect students' participation in physical exercise but do not affect their prosocial tendencies. A credible instrument variable must meet the following two conditions. First, it must directly have an influence on whether students regularly participate in physical exercise. Secondly, it must be strictly exogenous, not directly affecting the dependent variables, and there must be no direct causal relationship with the dependent variables.

The proportion of students of other ages in the school who regularly participate in physical exercise can be used as an instrumental variable to determine whether students often participate in physical exercise. There are three main factors influencing students' regular participation in physical exercise. The first is one's own preferences. If a student enjoys physical exercise, he will often participate in physical exercise. The second is the sports facilities in the school. Participating in physical exercise requires certain prerequisites, such as a track that is required for running and a basketball court that is required to play basketball. The third is the amount of participation in exercise. If the people around you do not like physical exercise, your enthusiasm for regular participation in physical exercise may be affected. The proportion of students in other classes who regularly participate in physical exercise reflects whether the entire school has basic physical exercise facilities and whether there is a positive climate that encourages participation in physical 
exercise. However, the instrumental variables processed in this way cannot exclude the influence of community noise. Studies have shown that the neighborhood effect has a very important impact on children's performance. As a result, it may not be possible to be strictly exogenous.

Considering these limitations, we will use the PSM method to estimate the causal relationship between physical exercise and students' prosocial behavior. The basic idea of the PSM estimation method is to find two groups of students who match each other. One group often participates in physical exercise, and the other does not. Then, their average prosocial behavior levels will be compared.

Suppose that we use the 0-1 variable sport to distinguish whether students often participate in physical exercise: if the student often participates in physical exercise, the value of sport is 1 ; otherwise its value is 0 . For a student $i$ who regularly participates in physical exercise, we define its potential prosocial behavior as proprefi. The average processing effect of regular participation in physical exercise on students' prosocial behavior performance is expressed as the difference between their actual prosocial behavior performance $\mathrm{E}\left(\right.$ propref $_{0} \mid$ sport $\left.=1\right)$, and the prosocial behavior performance $\mathrm{E}\left(\right.$ proprefo $_{0} \mid$ sport $\left.=1\right)$ under the assumption that they do not regularly participate in physical exercise, namely:

$A T T=\mathrm{E}\left(\right.$ propre $_{1} \mid$ sport $\left.=1\right)-\mathrm{E}\left(\right.$ propre $_{0} \mid$ sport $\left.=1\right)$

Our sample is a cross-sectional one, and therefore, we can only observe students in one state. In other words, we can only observe the actual prosocial behaviors of students who regularly participate in physical exercise, rather than infrequently. The approach of PSM is to use the prosocial behavior of a student who matches the student but who does not regularly participate in physical exercise as the student's potential prosocial behavior.

An intuitive matching method is to match based on observable personal characteristics, and then analyze. However, when there are additional feature variables for matching, direct matching may encounter the problem of 'dimension curse' (Rosenbaum and Rubin, 1982). Therefore, Rosenbaum and Rubin (1982) [40] proposed that the probability of an individual entering the processing group (in this study, it indicates whether or not they often participate in physical exercise) can be estimated based on the individual's characteristic information, and then the probability can be matched. Because the dimension of matching changes from multiple dimensions to one dimension, the efficiency of matching is greatly increased, and the matching results are basically the same. The probability used here for matching is also called the propensity score, and this is the origin of the name PSM.

To be able to use PSM, two assumptions must be met in the current study. The first is the assumption of conditional independence. That is to say, the control variable $\mathrm{X}$ may not only affect the decision of whether students often participate in physical exercise, but also the performance of students' prosocial behavior. Nonetheless, the decision of whether students often participate in physical exercise cannot affect these variables. Therefore, after controlling for these variables, whether students often participate in physical exercise is random, and the difference in student behavior comes from the processing of whether students often participate in physical exercise. The second is the joint support hypothesis. The common support hypothesis requires that students with certain characteristics must have a positive probability of whether they often participate in physical exercise or do not often participate in physical exercise. This indicates that the probabilities of students participating in physical exercise under different conditions must overlap. This second hypothesis actually says that matching objects among students who do not often participate in physical exercise must be found. Otherwise, it will be impossible to analyze the effects of physical exercise. Under the condition of satisfying the above two assumptions, the difference in the performance of students' prosocial behavior is the difference caused by whether they often participate in physical exercise within the common support, namely:

$A T T=E\left[\right.$ propre $f_{1} \mid$ sport $\left.=1, \mathrm{P}(\mathrm{X})\right]-E\left[\right.$ propre $_{0} \mid$ sport $\left.=1, \mathrm{P}(\mathrm{X})\right]$

The last issue is about the choice of matching methods, that is, how to match propensity scores. The matching methods that can be selected include nearest neighbor matching, 
radius matching, kernel matching, and local linear regression matching. The results obtained by using different matching methods should be consistent. If different estimation results are obtained from different matching methods, this indicates that the influence of physical exercise is uncertain. Therefore, looking at different matching methods from a certain angle can also be regarded as a robustness test.

\section{Results}

\subsection{Baseline results: OLS estimation}

We first used OLS to estimate the relationship between regular participation in physical exercise and the prosocial behavior of students. The estimated results are shown in Table 2, and indicate that there is a significant correlation between regular participation in physical exercise and the scores of students' prosocial behaviors. On average, regular participation in physical exercise improved students' prosocial behavior by 0.2 standard points. After we controlled for various variables, the results were still significant. We also discovered that in different household registration samples, the effects of physical exercise were similar, but the estimated coefficients in the household registration sample were slightly larger than those in the other two samples, although the difference was not significant.

Table 2. OLS estimation results.

\begin{tabular}{|c|c|c|c|c|}
\hline Variable & Full sample & Rural household & Urban household & Residential household \\
\hline \multirow{2}{*}{ Regular physical exercise } & $0.2142^{* * * *}$ & $0.2093^{* * *}$ & $0.1974^{* * *}$ & $0.2360^{* * *}$ \\
\hline & $(0.0285)$ & $(0.0402)$ & $(0.0391)$ & $(0.0551)$ \\
\hline \multirow{2}{*}{ Female } & $0.1899^{* * * *}$ & $0.2185^{* * *}$ & $0.1201^{* * *}$ & $0.2019^{* * *}$ \\
\hline & $(0.0235)$ & $(0.0343)$ & $(0.0439)$ & $(0.0469)$ \\
\hline \multirow{2}{*}{ Age } & -0.0105 & -0.0031 & -0.0472 & -0.0068 \\
\hline & $(0.0166)$ & $(0.0222)$ & $(0.0387)$ & $(0.0393)$ \\
\hline \multirow{2}{*}{ Han nationality } & $0.1584^{* * * *}$ & 0.1267 & 0.1271 & $0.2676^{*}$ \\
\hline & $(0.0585)$ & $(0.0883)$ & $(0.0958)$ & $(0.1545)$ \\
\hline \multirow{2}{*}{ BMI index } & -0.0050 & -0.0054 & -0.0051 & -0.0078 \\
\hline & $(0.0035)$ & $(0.0049)$ & $(0.0061)$ & $(0.0076)$ \\
\hline \multirow{2}{*}{ Cognitive ability } & $0.3255^{* * *}$ & $0.3585^{* * *}$ & $0.2916^{* * *}$ & $0.2286^{* *}$ \\
\hline & $(0.0513)$ & $(0.0604)$ & $(0.0868)$ & $(0.1106)$ \\
\hline \multirow{2}{*}{ Number of siblings } & -0.0053 & -0.0036 & -0.0507 & 0.0029 \\
\hline & $(0.0157)$ & $(0.0174)$ & $(0.0441)$ & $(0.0447)$ \\
\hline \multirow{2}{*}{ Mother's years of education } & $0.0087^{*}$ & 0.0087 & 0.0076 & 0.0094 \\
\hline & $(0.0049)$ & $(0.0065)$ & $(0.0089)$ & $(0.0108)$ \\
\hline \multirow{2}{*}{ Father's years of education } & $0.0160^{* * * *}$ & $0.0173^{* *}$ & 0.0092 & $0.0261^{* *}$ \\
\hline & $(0.0054)$ & $(0.0078)$ & $(0.0099)$ & $(0.0103)$ \\
\hline \multirow{2}{*}{ Urban household } & 0.0356 & & & \\
\hline & $(0.0364)$ & & & \\
\hline Residential household & $\begin{array}{l}-0.0012 \\
(0.0378)\end{array}$ & & & \\
\hline \multirow{2}{*}{ Constant } & $-1.3526^{* * *}$ & $-1.5543 * * *$ & -0.5529 & $-1.2855^{*}$ \\
\hline & $(0.3095)$ & $(0.3979)$ & $(0.6283)$ & $(0.6674)$ \\
\hline \multirow{2}{*}{$\begin{array}{l}\text { Observed value } \\
\text { R-squared }\end{array}$} & 7,666 & 4,037 & 2,098 & 1,531 \\
\hline & 0.0848 & 0.0900 & 0.0736 & 0.0972 \\
\hline
\end{tabular}

Note: In the parentheses is the standard error of the cluster at the school level. We also controlled for county-level virtual fixed effects.

For the estimation results of the other control variables, the variables that have the greatest impact on students' prosocial behavior include gender (whether female), cognitive ability, and father's years of education. There was a significant positive correlation with students' prosocial behavior scores for these three variables. Specifically, for a female student, the prosocial behavior score was approximately 0.2 standard points higher than that of a male student. For every $1 \%$ increase in cognitive ability, the student's prosocial behavior score will increase by approximately 0.3 standard points. For every additional 
year of education a father receives, his child's prosocial behavior score will increase by approximately 0.02 standard points. The effects of other variables were not robust, and therefore, we can ignore them.

\subsection{PSM results}

Before estimating PSM, we must first estimate the tendency of individuals to regularly participate in physical exercise. Here, OLS is generally used to estimate, and then we can obtain the influencing factors that affect whether students participate in physical exercise. The estimated results are shown in Table 3.

Table 3. Estimation of the tendency to participate in physical exercise.

\begin{tabular}{|c|c|c|c|c|}
\hline factors & Full sample & Rural household & Urban household & Residential household \\
\hline \multirow{2}{*}{ female } & 0.0081 & 0.0154 & -0.0082 & 0.0060 \\
\hline & $(0.0142)$ & $(0.0207)$ & $(0.0239)$ & $(0.0245)$ \\
\hline \multirow{2}{*}{ age 12} & 0.0055 & 0.0040 & -0.0008 & 0.0220 \\
\hline & $(0.0105)$ & $(0.0124)$ & $(0.0168)$ & $(0.0224)$ \\
\hline \multirow{2}{*}{ han } & 0.0071 & 0.0248 & -0.0262 & 0.0023 \\
\hline & $(0.0283)$ & $(0.0372)$ & $(0.0432)$ & $(0.0616)$ \\
\hline \multirow{2}{*}{ bmi } & -0.0005 & 0.0013 & 0.0024 & $-0.0074 * * *$ \\
\hline & $(0.0016)$ & $(0.0025)$ & $(0.0032)$ & $(0.0028)$ \\
\hline \multirow{2}{*}{$\operatorname{cog} \ln$} & $0.1125 * * *$ & $0.1340 * * *$ & $0.1240 * * *$ & 0.0343 \\
\hline & $(0.0265)$ & $(0.0322)$ & $(0.0451)$ & $(0.0416)$ \\
\hline \multirow{2}{*}{ sibling } & -0.0025 & 0.0014 & -0.0215 & 0.0115 \\
\hline & $(0.0084)$ & $(0.0104)$ & $(0.0182)$ & $(0.0187)$ \\
\hline \multirow{2}{*}{ eduy_mo } & 0.0025 & -0.0013 & 0.0003 & $0.0110 * *$ \\
\hline & $(0.0024)$ & $(0.0032)$ & $(0.0052)$ & $(0.0049)$ \\
\hline \multirow{2}{*}{ eduy_fa } & $0.0083 * * *$ & $0.0098 * * *$ & 0.0003 & $0.0115 * *$ \\
\hline & $(0.0025)$ & $(0.0034)$ & $(0.0055)$ & $(0.0057)$ \\
\hline \multirow{2}{*}{ hukou2 } & -0.0117 & & & \\
\hline & $(0.0189)$ & & & \\
\hline \multirow{2}{*}{ hukou3 } & -0.0046 & & & \\
\hline & $(0.0201)$ & & & \\
\hline \multirow{2}{*}{ Constant } & -0.1601 & -0.2561 & -0.0327 & -0.0724 \\
\hline & $(0.1549)$ & $(0.1895)$ & $(0.2572)$ & $(0.3295)$ \\
\hline Observations & 7,666 & 4,037 & 2,098 & 1,531 \\
\hline R-squared & 0.0938 & 0.0834 & 0.1169 & 0.1459 \\
\hline
\end{tabular}

Note: In the brackets is the standard error from the cluster to the school level. We also controlled for county fixed effects. In order to save space, the estimation results are omitted here. The ${ }^{*},{ }^{* * * *}$ represent the significance at the level of $10 \%$, $5 \%$, and $1 \%$, respectively.

Table 3 shows that the main effective factors for regular participation in physical exercise are personal cognitive ability and education level of the father. However, the estimation results vary in different samples. In rural household registration, the main factors that affect whether students often participate in physical exercise are cognitive ability and father's education years. In urban household registration, the main factor is the number of years of students' cognitive ability. In the residential household registration, the influencing factors include the individual's health level (BMI index), the mother's years of education, and the father's years of education.

On the basis of estimating the influencing factors for whether to regularly participate in physical exercise, we obtained the propensity score for whether each student participated in physical exercise. Figure 2 shows the distribution of propensity scores for whether individuals often participate in physical exercise. It can be seen from Table 2 that the tendency scores for regular participation in physical exercise are more concentrated overall in the high segment. However, there are obvious overlaps between the two, which also shows that the common support hypothesis for propensity score estimation is valid. We can use PSM to estimate the impact of regular participation on physical exercise. 


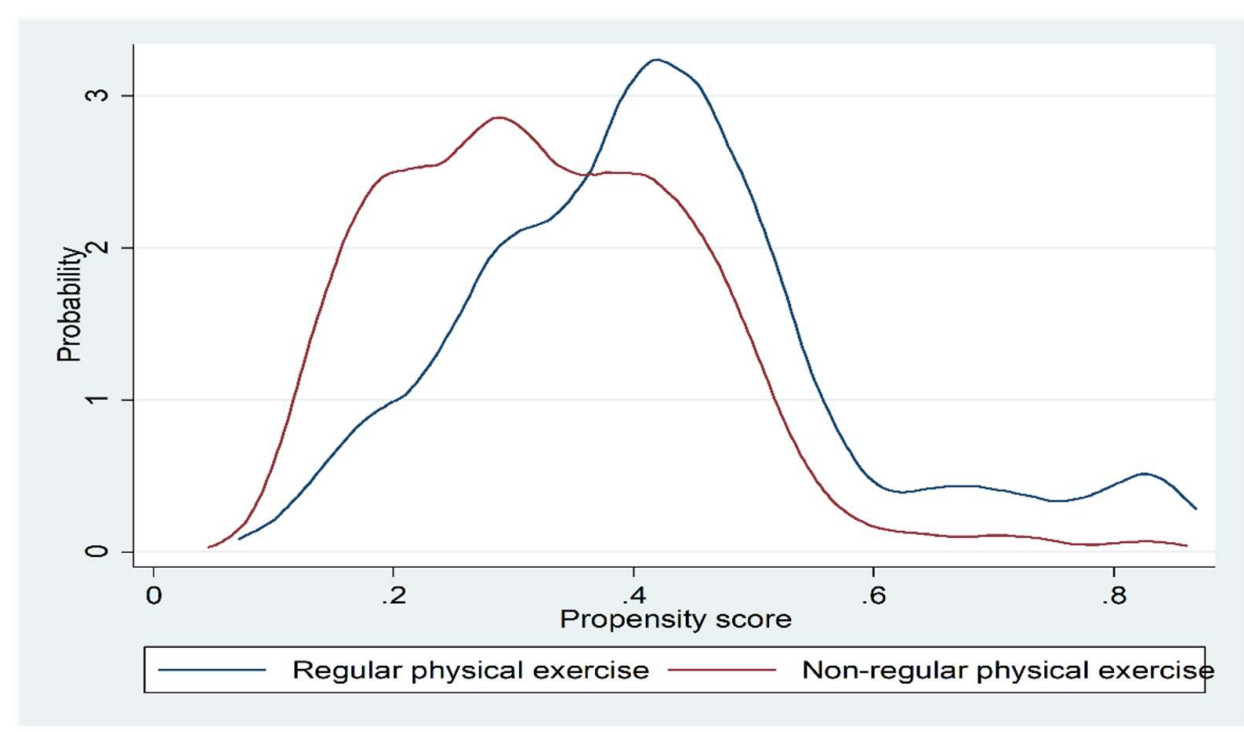

Figure 2. Propensity score distribution of whether to regularly participate in physical exercise.

Then, we used PSM to estimate the impact of regular participation in physical exercise. The estimated results are shown in Table 4, which indicates that regular participation in physical exercise does significantly improve students' prosocial behavior. On average, regular participation in physical exercise increased students' prosocial behavior tendency by more than 0.2 standard points. This result is very close to the OLS estimation result. The estimation results using samples of rural household, urban household, and residential household are nearly the same.

Table 4. PSM estimation results.

\begin{tabular}{ccccc}
\hline Matching method & Full sample & Rural household & Urban household & Residential household \\
\hline \multirow{2}{*}{1 to 1 match } & $0.2046^{* * *}$ & $0.2537^{* * *}$ & $0.2473^{* * *}$ & $0.2604^{* * *}$ \\
\cline { 2 - 5 } & $(0.0449)$ & $(0.0476)$ & $(0.0819)$ & $(0.0904)$ \\
\cline { 2 - 5 } Radius match & $0.2274^{* * *}$ & $0.2283^{* * *}$ & $0.2121^{* * *}$ & $0.2397^{* * *}$ \\
\cline { 2 - 5 } & $(0.0253)$ & $(0.0328)$ & $(0.0509)$ & $(0.0760)$ \\
\cline { 2 - 5 } Kernel match & $0.2254^{* * *}$ & $0.2306^{* * *}$ & $0.2110^{* * *}$ & $\left(0.2425^{* * *}\right.$ \\
\hline \multirow{2}{*}{ Local least squares regression matching } & $(0.0244)$ & $(0.0335)$ & $(0.0435)$ & $0.0618)$ \\
\hline & $0.2318^{* * *}$ & $0.2238^{* * *}$ & $0.2334^{* * *}$ & $0.2422^{* * *}$ \\
\hline
\end{tabular}

Note: In the brackets is the standard error of bootstrap 500 times. The matching variable is the same as the OLS estimate. The radius of one-to-one matching, the radius of radius matching, the bandwidth of kernel matching, and the bandwidth of local least squares regression matching are all set to 0.01 . The ${ }^{*},{ }^{* *},{ }^{* *}$ represent significance at the level of $10 \%, 5 \%$, and $1 \%$, respectively.

\subsection{Balance test}

The reliability of the matching results also depends on whether the post-matching processing group and the control group are comparable, i.e., whether their basic characteristics are similar. We can test the similarity of the basic characteristics between the treatment group and the control group through a balance test. The idea of the balance test is that the mean values of characteristic variables of the treatment group and the control group should not be significantly different after matching.

Table 5 reports the results of the balance test. In Table 5, the treatment group represents regular participation in physical exercise, and the control group represents infrequent participation. Table 5 shows that in addition to gender and BMI index, there are significant differences between the treatment group and the control group of other variables before matching, which indicates that direct comparison between them may lead to larger estimation errors. After matching, no significant difference between the treatment 
group and the control group for all variables showed that matching eliminates observable heterogeneity, which subsequently resulted in the treatment group and the control group being comparable.

Table 5. Balance test.

\begin{tabular}{|c|c|c|c|c|c|}
\hline Factors & $\begin{array}{c}\text { Matching } \\
\text { status }\end{array}$ & $\begin{array}{c}\text { Treatment } \\
\text { group }\end{array}$ & $\begin{array}{c}\text { Control } \\
\text { group }\end{array}$ & $\begin{array}{l}\text { Deviation } \\
\text { ratio (\%) }\end{array}$ & $\begin{array}{c}T \\
\text { statistics } \\
\end{array}$ \\
\hline \multirow{2}{*}{ Gender } & Before matching & 0.4940 & 0.4805 & 2.7 & 1.13 \\
\hline & After matching & 0.4940 & 0.4756 & 3.7 & 1.37 \\
\hline \multirow{2}{*}{ Age } & Before matching & 11.4870 & 11.5420 & -8.1 & $-3.35^{* * *}$ \\
\hline & After matching & 11.4870 & 11.4920 & -0.7 & -0.29 \\
\hline \multirow{2}{*}{ Han nationality } & Before matching & 0.9305 & 0.9058 & 9 & $3.71^{* * *}$ \\
\hline & After matching & 0.9305 & 0.9352 & -1.7 & -0.7 \\
\hline \multirow{2}{*}{ BMI index } & Before matching & 19.2640 & 19.1510 & 3.4 & 1.43 \\
\hline & After matching & 19.2640 & 19.2620 & 0.1 & 0.02 \\
\hline \multirow{2}{*}{ Cognitive ability } & Before matching & 3.1682 & 3.0873 & 26.5 & $10.94^{* * *}$ \\
\hline & After matching & 3.1682 & 3.1669 & 0.4 & 0.16 \\
\hline \multirow{2}{*}{ Number of siblings } & Before matching & 0.6353 & 0.7366 & -12.5 & $-5.21^{* * *}$ \\
\hline & After matching & 0.6353 & 0.6559 & -2.5 & -1 \\
\hline \multirow{2}{*}{ Mother's years of education } & Before matching & 10.2220 & 9.4648 & 23.1 & $9.7^{* * *}$ \\
\hline & After matching & 10.2220 & 10.1930 & 0.9 & 0.34 \\
\hline \multirow{2}{*}{ Father's years of education } & Before matching & 10.8760 & 10.1820 & 24.4 & $10.26^{* * *}$ \\
\hline & After matching & 10.8760 & 10.8280 & 1.7 & 0.62 \\
\hline
\end{tabular}

${ }^{1}$ Note: The ${ }^{*}, * * * *$ represent significance at the level of $10 \%, 5 \%$, and $1 \%$, respectively.

\subsection{Robustness test}

Finally, it is necessary to test the robustness or sensitivity of the estimated results. Our previous estimates are matching analyses based on observable heterogeneity. There may be unobservable heterogeneity that affects the tendency of a student to participate in physical exercise, which leads to unreliable results. We can use the Rosenbaum boundary test to examine whether the estimation result can be maintained when a disturbance exists in the heterogeneity [41]. The basic idea of Rosenbaum boundary estimation is to use it to determine whether the estimation result will change when unobservable heterogeneity increases by a certain percentage.

The Rosenbaum boundary test results are shown in Table 6 . The $\Gamma$ reflects the disturbance ratio. When $\Gamma=1$, this indicates that there is no disturbance. When $\Gamma=1.1$, this indicates that the disturbance increases by $10 \%$, and so on. Table 6 shows that when $\Gamma=$ 1.9 , the upper limit significance level is $6.02 \%$. The upper limit significance level is below $1 \%$ when $\Gamma<1.9$. and the lower limits of the confidence intervals are greater than zero. This indicates that only when the disturbance caused by unobservable heterogeneity is very large will it lead to significant differences in the estimated results and cause the results of participating in physical exercise to be insignificant, which shows that the estimation results in this study are robust.

Table 6. Rosenbaum boundary test results

\begin{tabular}{ccccc}
\hline$\Gamma$ & $\begin{array}{c}\text { Upper limit of } \\
\text { significance level }\end{array}$ & $\begin{array}{c}\text { Lower limit of } \\
\text { significance level }\end{array}$ & $\begin{array}{c}\text { Lower limit of confidence } \\
\text { interval }\end{array}$ & $\begin{array}{c}\text { Upper limit of confidence } \\
\text { interval }\end{array}$ \\
\hline 1.0 & 0.0000 & 0.0000 & 0.2785 & 0.2785 \\
1.1 & 0.0000 & 0.0000 & 0.2534 & 0.3017 \\
1.2 & 0.0000 & 0.0000 & 0.2267 & 0.3236 \\
\hline
\end{tabular}




\begin{tabular}{lllll}
\hline 1.3 & 0.0000 & 0.0000 & 0.1817 & 0.3717 \\
1.4 & 0.0000 & 0.0000 & 0.1173 & 0.4287 \\
1.5 & 0.0000 & 0.0000 & 0.0901 & 0.4579 \\
1.6 & 0.0000 & 0.0000 & 0.0739 & 0.4761 \\
1.7 & 0.0000 & 0.0000 & 0.0573 & 0.4921 \\
1.8 & 0.0034 & 0.0000 & 0.0413 & 0.5070 \\
1.9 & 0.0602 & 0.0000 & 0.0259 & 0.5193 \\
2.0 & 0.3241 & 0.0000 & 0.0091 & 0.5302 \\
\hline
\end{tabular}

\subsection{Heterogeneity analysis}

In examining who will receive greater benefit from the exercises, we divided the samples into two subsamples in terms of gender and the father's education. Considering that the median of the father's education is nine years, we used nine years of schooling as a threshold and divided the sample into two subsamples denoted as "low education" and "high education." The results of the heterogeneity analysis are shown in Table 6, which shows that male students receive significantly more benefits than female students. Similarly, students from families with high fathers' education will enjoy considerably more improvement in their prosocial behaviors.

Table 7. Results of heterogeneity analysis.

\begin{tabular}{|c|c|c|c|c|}
\hline Matching method & Female & Male & Low Education & High Education \\
\hline \multirow{2}{*}{1 to 1 match } & $0.1845^{* * *}$ & $0.2576^{* * *}$ & $0.1839^{*}$ & $0.2640^{* * *}$ \\
\hline & $(0.0529)$ & $(0.0382)$ & $(0.1041)$ & $(0.0385)$ \\
\hline \multirow{2}{*}{ Radius match } & $0.1711^{* * *}$ & $0.2283^{* * *}$ & $0.1952^{* * *}$ & $0.2456^{* * *}$ \\
\hline & $(0.0380)$ & $(0.0328)$ & $(0.0509)$ & $(0.0760)$ \\
\hline \multirow{2}{*}{ Kernel match } & $0.1783^{* * *}$ & $0.2536^{* * *}$ & $0.1941^{* * *}$ & $0.2486^{* * *}$ \\
\hline & $(0.0339)$ & $(0.0399)$ & $(0.0380)$ & $(0.0372)$ \\
\hline \multirow{2}{*}{ Local least squares regression matching } & $0.1700^{* * *}$ & $0.2576^{* * *}$ & $0.2036^{* * *}$ & $0.2485^{* * *}$ \\
\hline & $(0.0386)$ & $(0.0382)$ & $(0.0425)$ & $(0.0475)$ \\
\hline Observations & 3724 & 3956 & 4269 & 3411 \\
\hline
\end{tabular}

\section{Discussion}

It is generally believed that physical exercise has a promoting effect on students' physical health, mental health, and learning performance. In addition, physical exercise may also improve the moral quality of students, thereby promoting the improvement of interpersonal relationships and then further improving students' performance in all aspects. However, few studies have been performed to determine whether physical exercise will encourage students' morality.

Based on the 2014-2015 National Educational Panel Survey and using the PSM method, the impact of physical exercise on students' prosocial behavior was examined in the current study. The results of PSM estimation show that regular participation in physical exercise significantly improves students' prosocial behavior scores by more than 0.2 standard points. The robustness test shows that the estimation results in this study are robust.

We further conducted a heterogeneity analysis to determine who receives the greater benefit from physical activity. The results show that males and students whose father's years of schooling are greater than 9 years will enjoy more improvement in their prosocial behavior.

\section{Conclusions}

The research in this article shows that encouraging students to participate in physical exercise results in effectively improving the harmony and learning efficiency of the entire 
group. Therefore, schools and class groups must create an atmosphere for physical exercise and also create conditions to promote students' active participation in physical exercise from all aspects.

Author Contributions: Conceptualization, Y.W. and H.S.; methodology, Y.W. and L.L.; formal analysis, Y.W.; investigation, Y.W.; resources, H.S.; data curation,Y.W.; writing-original draft preparation, Y.W.; writing - review and editing, Y.W. and L.L.; project administration, Y.W.; funding acquisition, Y.W. All authors have read and agreed to the published version of the manuscript."

Funding: This research was funded by the General Project of Philosophy and Social Science Research in Jiangsu Universities, grant number 2019SJA0122.

\section{References}

[1] Hausenblas H A, Fallon E A. Exercise and body image: A meta-analysis. Psychology and health 2006, 21 (1): 33-47.

[2] Szuhany K L, Bugatti M, Otto M W. A meta-analytic review of the effects of exercise on brain-derived neurotrophic factor. Journal of psychiatric research 2015, 60: 56-64.

[3] Owens S .et al. Visceal adipose tissue and markers of the insulin resistance aydrome in obese black and white teenages. Obes Res, 2000, 8(4): 287-293.

[4] Caprara G V, Alessandri G, Eisenberg N. Prosociality: the contribution of traits, values, and self-efficacy beliefs. Journal of personality and social psychology, 2012, 102(6): 1289.

[5] Van Tongeren D R, Green J D. Combating meaninglessness: On the automatic defense of meaning. Personality and Social Psychology Bulletin, 2010, 36(10): 1372-1384.

[6] Fehr E, Goette L, Zehnder C. A behavioral account of the labor market: The role of fairness concerns. Annu. Rev. Econ. 2009, 1(1): 355-384.

[7] Carpenter J, Seki E. Do social preferences increase productivity? Field experimental evidence from fishermen in Toyama Bay. Economic Inquiry, 2011, 49(2): 612-630.

[8] Kosse F, Deckers T, Pinger P, et al. The formation of prosociality: causal evidence on the role of social environment. Journal of Political Economy, 2020, 128(2): 434-467.

[9] Bahmani D S, Razazian N, Motl R W, et al. Physical activity interventions can improve emotion regulation and dimensions of empathy in persons with multiple sclerosis: An exploratory study. Multiple sclerosis and related disorders, 2020, $37: 101380$.

[10] Hillman C H, Buck S M, Themanson J R, et al. Aerobic fitness and cognitive development: Event-related brain potential and task performance indices of executive control in preadolescent children. Developmental psychology, 2009, 45(1): 114.

[11] Krebs DL, Van Hesteren F. The development of altruism: Toward an integrative model. Developmental Review, 1994, 14(2): 103158.

[12] Eisenberg, N., \& Fabes, R. A. Prosocial development.In P. Musser ( Eds. ), Handbook of child psychology: Social, emotional, and personality development. Wiley 1998, (pp. 701-778)

[13] Fabes R A, Carlo G, Kupanoff K, et al. Early adolescence and prosocial/moral behavior I: The role of individual processes. The Journal of Early Adolescence, 1999, 19(1): 5-16.

[14] Layous K, Nelson S K, Oberle E, et al. Kindness counts: Prompting prosocial behavior in preadolescents boosts peer acceptance and well-being. PloS one, 2012, 7(12): e51380.

[15] McMahon S D, Wernsman J, Parnes A L. Understanding prosocial behavior: The impact of empathy and gender among African American adolescents. Journal of adolescent health, 2006, 39(1): 135-137.

[16] Underwood B, Moore B. Perspective-taking and altruism. Psychological bulletin, 1982, 91(1): 143.

[17] Myers D G. Social Psychology, Post and Telecom Press. Beijing, 2005;475-519.

[18] Eisenberg N, Miller P A, Schaller M, et al. The role of sympathy and altruistic personality traits in helping: A reexamination. Journal of personality, 1989, 57(1): 41-67.

[19] Adelman H S, Taylor L. School counselors and school reform: New directions. Professional School Counseling, 2002, 5(4): 235.

[20] Van Tongeren D R, Green J D, Davis D E, et al. Prosociality enhances meaning in life. The Journal of Positive Psychology, 2016, 11(3): 225-236.

[21] Layous K, Nelson S K, Oberle E, et al. Kindness counts: Prompting prosocial behavior in preadolescents boosts peer acceptance and well-being. PloS one, 2012, 7(12): e51380.

[22] Laible D J, Carlo G, Roesch S C. Pathways to self-esteem in late adolescence: The role of parent and peer attachment, empathy, and social behaviours. Journal of adolescence, 2004, 27(6): 703-716.

[23] Van Tongeren D R, Green J D, Davis D E, et al. Prosociality enhances meaning in life. The Journal of Positive Psychology, 2016, 11(3): 225-236.

[24] Storch E A, Masia-Warner C. The relationship of peer victimization to social anxiety and loneliness in adolescent females. Journal of adolescence, 2004, 27(3): 351-362.

[25] Yang Y, Li P, Fu X, et al. Orientations to happiness and subjective well-being in Chinese adolescents: The roles of prosocial behavior and internet addictive behavior. Journal of Happiness Studies, 2017, 18(6): 1747-1762. 
[26] Sun R C F, Shek D T L. Life satisfaction, positive youth development, and problem behaviour among Chinese adolescents in Hong Kong. Social Indicators Research, 2010, 95(3): 455-474.

[27] Penner L A, Dovidio J F, Piliavin J A, et al. Prosocial behavior: Multilevel perspectives. Annu. Rev. Psychol., $2005,56: 365-392$.

[28] Donnelly J E, Hillman C H, Castelli D, et al. Physical activity, fitness, cognitive function, and academic achievement in children: a systematic review. Medicine and science in sports and exercise, 2016, 48(6): 1197.

[29] Harveson A T, Hannon J C, Brusseau T A, et al. Acute exercise and academic achievement in middle school students. International journal of environmental research and public health, 2019, 16(19): 3527.

[30] Colzato L S, Szapora Ozturk A, Pannekoek J N, et al. The impact of physical exercise on convergent and divergent thinking. Frontiers in human neuroscience, 2013, 7: 824.

[31] Castelli, D.M., Centeio, E.E., HWANG, J., et al. The history of physical activity and academic performance research: Informing the fu-ture. Monogr Soc Res Child Dev, 2014 ,79 (4) , 119-148.

[32] Mata J, Thompson R J, Gotlib I H. BDNF genotype moderates the relation between physical activity and depressive symptoms. Health psychology, 2010, 29(2): 130.

[33] Goodwin R D. Association between physical activity and mental disorders among adults in the United States. Preventive medicine, 2003, 36(6): 698-703.

[34] Biddle S J H, Asare M. Physical activity and mental health in children and adolescents: a review of reviews. British journal of sports medicine, 2011, 45(11): 886-895.

[35] Vocks, S., Hechler, T., Rohrig, S., \& Legenbauer, T. Effects of a physical exercise session on state body image: The influence of pre-experimental body dissatisfaction and concerns about weight and shape. Psychology and Health,2009,24(6), 713-728.

[36] Caldwell K, Harrison M, Adams M, et al. Effect of Pilates and taiji quan training on self-efficacy, sleep quality, mood, and physical performance of college students. Journal of Bodywork \& Movement Therapies, 2009, 13(2):155-163.

[37] Ede A, Hwang S, Feltz D L . Current directions in self-efficacy research in sport. Revista Iberoamericana De Psicología Del Ejercicio Y El Deporte, 2011, 6:181-201.

[38] Campbell A L. Impact of choice on student motivation, autonomy, competence, and enjoyment in high school physical education. University of Virginia, 2012.

[39] Moore, Q. L., Kulesza, C., Kimbro, R., Flores, D., \& Jackson, F. The role of prosocial behavior in promoting physical activity, as an indicator of resilience, in a low-income neighborhood. Behavioral Medicine, 2020,46(3-4), 353-365.

[40] Rosenbaum, P.R., \& Rubin, D.B. The Central Role of the Propensity Score in Observational Studies for Causal Effects. Biometrika, 1983.,70(1), 41-55.

[41] Rosenbaum, P.R. Observational Studies. 2nd edition. New York: Springer. 2002 